\title{
Thermodynamic analysis of indexes of operation of the engine with direct fuel injection for idle speed and acceleration
}

\author{
Ireneusz Pielecha ${ }^{1} \cdot$ Wojciech Cieślik $^{1}$
}

Received: 14 November 2015/Accepted: 13 May 2016/Published online: 26 May 2016

(c) The Author(s) 2016. This article is published with open access at Springerlink.com

\begin{abstract}
Contemporary requirements for combustion engines are aimed mainly at obtaining significant parameter values of their operation at simultaneously low fuel consumption and reduced exhaust emission. Despite the fact that combustion engines utilize diverse load conditions, the idle speed share in the whole range of their operation is significant. The percentage of combustion engines with spark-ignition direct injection (SI DI) in the total number of spark-ignition engines is increasing. It means that the method of the mixture preparation is an important factor in SI DI engine, also for idle speed. In the tests was analysed the SI engine preparing the mixture with a dose of injected fuel (air-guided type) in conditions of the idle speed. Idle speed control is a critical issue in engine control fields. Essentially, it is a highly nonlinear and timevarying problem. Its performance has a significant impact on fuel economy and emission levels. The engine operation indexes were determined, and with the use of coefficient of variation, the variation of the cycle was estimated. Article contains the three-stage division, taking into account the variable measuring modes where was analysed the work condition during the idling, free acceleration of combustion engine and car acceleration. From numerous operational indexes of the engine operation were selected those, which in the best way characterize engine operation for idle speed.
\end{abstract}

Keywords Combustion engine $\cdot$ Indicating research · Idling · Cycle variation · Transient operational conditions . Engine acceleration · Vehicle acceleration

Ireneusz Pielecha

ireneusz.pielecha@put.poznan.pl

1 Poznan University of Technology, Poznan, Poland

\section{Introduction}

Spark-ignition engines used in today's vehicles do not constitute as uniform group in terms of solutions such as injection and combustion systems, as the compression ignition (CI) engines do. Also CI engine nowadays uses different types of fuel, which require appropriate construction changes $[1,2]$. Today, it is one of the research directions made by Sing [3]. The designs of the combustion systems for engines with spark ignition include the systems of indirect injection into the inlet duct (low-pressure injection) and of direct injection into the cylinder (mediumpressure injection) [4]. Few designs which are a combination of those two systems were widely applied (e.g. in the Lexus engine 2GR-FSE and in Audi engine-EA888 of the third generation, in which the direct and indirect fuel injection is utilized). Numerous designs of the direct gasoline injection system indicate the lack of satisfactory solutions of this type both in terms of operational parameters obtained and exhaust gases emission. The fuel injection to the cylinder should meet two requirements. First one, it should enable the homogeneous charge burning (used in the indirect injection systems, which causes, however, significant losses of the charge before supplying it to the closed cylinder volume). Secondly-which at present is the main research direction and development works-it should enable obtaining a heterogeneous (stratified) charge, which would make it possible to burn lean mixtures (such a strategy is available thanks to the application of medium-pressure, direct and multiple gasoline injection). In this respect, combustion systems of SI engines are getting similar to the combustion systems used in $\mathrm{CI}$ engines (e.g. use of a controlled self-ignition in the SI engine). These systems are currently the main subject of tests in the spark-ignition engines, as such an injection 
system allows for any quantitative and qualitative formation of the charge and affects the way it is later burnt. The macroscopic characteristic of fuel injection spray for SI DI engines research is made by Chen [5]. In research were analysed the important spray characteristics like penetration and spray angle. These parameters are crucial for the correct operation of the injection system.

Direct gasoline injection system is carried out by applying lateral or central positioning of the injector. The first solution gives time sufficient for the charge preparation for combustion (with no dose splitting), as the injection is possible before the piston reaches top dead centre (TDC). This time is used for the fuel evaporation and its preparation for combustion. At the same time, however, this layer is being diluted and the charge loses its stratification, the distribution of fuel in the cylinder becomes uneven, and this reduces the combustion efficiency.

Far more beneficial in this respect is the central localization of the injector in the combustion chamber. The problem then is, however, time reduction of the charge preparation (mixing and fuel evaporation) and the way the spark plug is located. It is also difficult to obtain a homogeneous charge, particularly under heavy loads (a large fuel dose injection without splitting it). Incorrect localization of the spark plug is the cause of carbon deposits formation on its electrodes, making it impossible to obtain the correct discharge. This, however, is much more favourable in case of stratified charges and engine operation with significant excess air ratio (it is possible to obtain values of $\lambda=3-5$ depending on how the fuel dose is split and how the charge is prepared). On the basis of the research carried out by Petersen et al., it was shown that in case of the SI DI engines the lack of combustion or incorrect combustion process is not caused by the failure of spark plug ignition, but by the improper charge preparation for combustion. Because of the problems with correct charge preparation and its combustion, in paper [4] was conducted partial analysis of fuel atomization with the use of an outward-opening injector, which is located centrally in the combustion chamber. For this purpose were used various multiple fuel injection techniques in order to obtain quantitative and qualitative information about the charge preparation for combustion.

Presented in the article are issues concerning dynamic operating conditions of the combustion engine. Complete knowledge in area of dynamic states can contribute to the ability to power supply of combustion engines by other fuels $[3,6-8]$ allowing the optimization of the operation under these conditions.

The construction of the article consists in the preface a presentation of the issues in the literature review and description of engine transient operational conditions. In the next section article presents thesis which through use of the presented research methodology has been proved on results of the analysis in three-stage mode (during the idling, free acceleration of engine and vehicle acceleration). At the end paper has been summarized.

\section{Variation in engine operation during idling: literature review}

In modern SI engines, an efficient idle speed performance is required to fulfil the ever-increasing requirements on fuel consumption, vehicle driveability and pollutant emissions. Basically, the idle speed control problem is a compromise between low engine speed for fuel saving, minimum emissions and powertrain vibrations. Due to numerous participation of idling engine speed in the driving cycle is subject raised in many works for optimization process $[9,10]$.

It is thought that the engine operation repeatability at idling speed is a key requirement allowing the use of stratified and lean mixtures. Minor changes in the process caused by slow combustion lead to undesired engine vibrations. Significant combustion dynamics can cause an increase in the hydrocarbons emission [10]. The results of the tests by Heywood presented in [11] (concerning mainly the SI engines) show that the coefficient of variation reduction can lead to fuel consumption reduction by $8 \%$ and that the coefficient of variation value greater than $10 \%$ leads to the engine unsteady operation. The study [12] relating to variations of the engine operation proved that intake of $20 \%$ of recirculated exhaust gases increases the variation of engine operation by more than $10 \%$ (this variation was highlighted by the coefficient of variation of the mean indicated pressure). However, the use of increased compression ratio reduces this value. It results from the reduction of the laminar air speed and an increase of the intensity of vibrations during this procedure. These findings are also confirmed in the study [10], which shows that the increase in laminar combustion speed of LPG leads to reduction of the $\mathrm{CoV}$ of the mean indicated pressure to about $2 \%$ (for changes of the excess air ratio ranging from 1.0 to 1.4). While supplying the gasoline engine in the same range of variations of the excess air ratio, $\mathrm{CoV}(\mathrm{I}-$ MEP) obtains the value of $4.5 \%$.

Ozdor et al. [13] divide the factors affecting variation of the combustion process into four categories: components of the mixture, inlet of the charge, characteristics of the ignition system and the process of swirling in the cylinder. Pundir et al. [14] stated that the inlet charge has the least impact on the process variability if the combustible mixture is stoichiometric.

Conditions of variability of the engine operation were defined on the basis of the coefficient of variation of a given parameter $X$, defined as: 
$\operatorname{CoV}_{\mathrm{X}}=\frac{\sigma}{\mu}$

where $\sigma$-is the standard deviation of parameter $X$ and $\mu$ is the mean value of $X$ from measurements. The range distribution analysis of values was completed with the scenes SK-skewness of the numerical distribution (determines the asymmetry of the distribution of the analysed values):

$\mathrm{SK}=\frac{n \sum\left(x_{\mathrm{i}}-x_{\mathrm{m}}\right)^{3}}{(n-1)(n-2) s^{3}}$

where $n$-is the observations number, $x_{\mathrm{i}}$-is the result of the subsequent observation, $x_{\mathrm{m}}$-is the mean value and $s-$ is the standard deviation.

This coefficient with a value equal to zero proves perfectly symmetrical distribution and with a value of more than zero indicates right-skewed distribution, while for values below zero it indicates left-skewed (negatively skewed) distribution.

Thanks to the use of a large number of measurement data (taking into account at least 30 samples) the statistical accuracy was maintained $[15,16]$.

\section{Engine transient operational conditions}

Engine transient operational conditions demand different than the above-mentioned requirements. During rapid acceleration, the engine operation in terms of external characteristics is desirable. During the tests of eco-driving strategy by Saboohi and Farzaneh [17], it was found that for fixed driving conditions at a speed of $50 \mathrm{kph}$ is required only $5 \mathrm{~kW}$ engine power. The engine or vehicle rapid acceleration requires the availability of a full engine power at a given engine speed. Due to the incomplete identification of the phenomena prevailing during the SI DI engine transient operational conditions, the research was undertaken to determine the operation indexes specific including the thermodynamic indexes definition of accompanying processes. The issue is important due to the increased share of SI DI engines where the charge is combusted with the use of spray-guided method (formation of the charge by the fuel spray) [18].

The characteristics of the torque and the method of control in the propulsion system are those components of the drive system which attract a lot of attention nowadays $[19,20]$.

The driving force $F_{\mathrm{n}}$ occurring at the edge of the wheel contact with the ground depends on:

- engine torque $M_{\mathrm{o}}$ and its characteristics in the field of engine operation,
- total transmission ratio $i_{\mathrm{c}}$ in the propulsion system,

- the propulsion system type-from which the torque transmission efficiency $h_{\mathrm{p}}$ is dependant, which enables determination of the entire drive system efficiency,

- from the circle dynamic radius $\left(r_{\mathrm{d}}\right)$ which is the distance from the centre of the circle to the road surface.

$F_{\mathrm{n}}=\frac{M_{\mathrm{o}} \cdot i_{\mathrm{c}} \cdot h_{\mathrm{p}}}{r_{\mathrm{d}}} \leq\left(F_{\mathrm{n}}\right)_{\mathrm{gr}}$

Torque availability depends on the engine characteristics. In the engine acceleration process it is necessary to significantly increase the engine effective power. In accordance with Eq. (3) the effective power gain is possible as a result of the torque increase and the engine angular velocity:

$\Delta N_{\mathrm{e}}=\Delta M_{\mathrm{o}} \cdot \omega+M_{\mathrm{o}} \cdot \Delta \omega+\Delta M_{\mathrm{o}} \cdot \Delta \omega$

This equation, however, has certain limitations:

- the engine torque increase is limited by the available torque reserve value on the engine characteristics,

- an increase of the engine angular velocity causes a directly proportional gain of the effective power depending on the instantaneous speed.

The engine power increase as a result of the angular velocity increase requires overcoming of the mechanical inertia and the transmission system:

$N_{\mathrm{n}}=\eta_{\mathrm{m}} \cdot \omega_{\mathrm{s}}\left(M_{\mathrm{o}}-J \cdot \dot{\omega}_{\mathrm{s}}\right)$

where $J$-is the moment of masses inertia connected to the engine crankshaft, and $\eta_{\mathrm{m}}$-is the mechanical drive system efficiency.

From the analysis it ensures that because of the possibility of increasing the effective power, the highest possible torque reserve is desirable.

\section{Research thesis}

Research thesis was set out in the following way:

1. Estimation of the engine operation variation at idling speed determined only on the basis of the engine speed and mean indicated pressure is unreliable with regard to the thermodynamic indexes of this process.

2. Thermodynamic indexes of the engine operation while accelerating during standstill and during vehicle acceleration are fundamentally different; they arise from different engine load values, due to which the possibility of comparing them is limited.

The answer to so set out thesis of the paper makes it possible to extract the objectives of this research, which 
contribute to practical utilization of the determined engine operation thermodynamic indexes in the conditions considered.

\section{Research methodology}

The deterioration of the charge formation conditions in the combustion chamber makes it necessary to conduct the research in the field of combustion process in such engines, including idle speed conditions. The tests were conducted with the vehicle equipped with SI DI engine and the automatic 7-speed gearbox. The research methodology is presented in Fig. 1, which contains the three-stage division, taking into account the variable measuring modes.

Combination of a combustion engine with the automatic transmission allows now to use the new features of such drive systems. One of them is a feature that makes it possible to stop the vehicle without disconnecting the engine and the gearbox, without the necessity to use the brake pedal. The electric system controls power in the braking system, so that its value was greater than the force that enables movement of a vehicle. It follows that the stop of the vehicle may be carried out in two ways: using the $P$ position (park-disconnecting the drive system) or using the HOLD function (stopping without disconnecting the drive system). In both of these versions the control system uses different engine speed and engine load values.

The vehicle is equipped with a HOLD feature that enables vehicle immobilization after its stopping (without the necessity of using the brake constantly) without disconnecting the drive (Table 1). This means that idling can be obtained in two ways:

- after switching the gearbox into position P (parking) and

- after using the HOLD feature in position D (drive).

In the first case lack of disconnection of the drive results in obtaining the engine speed of $n=750 \mathrm{rpm}$ (using partial minimum load resulting from the automatic gearbox operation) and in the other case-after disconnecting the transmission-obtaining the engine speed of $650 \mathrm{rpm}$.

The first stage of the research was carried out during the standstill of the vehicle. One hundred and fifty consecutive

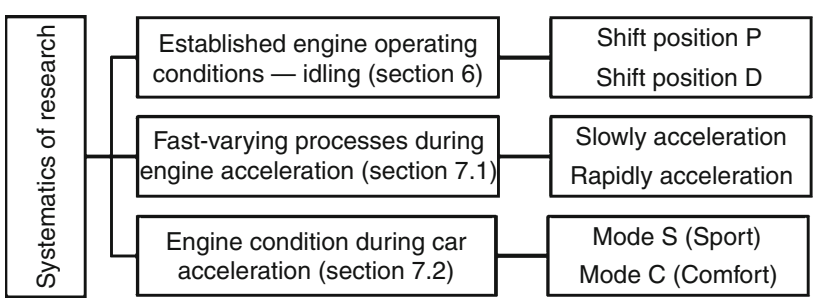

Fig. 1 Stages of the research cycles of engine operation were recorded and analysed. An analysis of the engine repeatability operation will enable the measurement of cylinder pressure in the combustion chamber with the use of a pressure sensor by AVL mounted in spark plug of the fourth cylinder. This cylinder is located closest to the place of engine speed measurement, because the engine speed sensor is located on the flywheel side. The cylinder pressure sensor with a measuring range of $0-20 \mathrm{MPa}$ had sensitivity of $11.91 \mathrm{pC} \mathrm{bar}^{-1}$. The signal from the pressure sensor along with the crankshaft crank angle measurement (number of teeth in the geared flywheel: 60-2) was recorded using the 8-channel measuring system AVL IndiSmart 621. For this purpose was used the original engine speed Hall sensor, and the measuring signal was recorded with the angular resolution of $\Delta \alpha=0.1^{\circ}$ of crankshaft rotation. The measuring system with the AVL Concerto software gives you the possibility of thermodynamic analysis of the engine cycles. The diagram of the measuring system is shown in Fig. 2.

The tests were carried out at two combustion engine idling speeds ( $n=650 \mathrm{rpm}$ and $750 \mathrm{rpm})$, at fixed thermal state of the engine (coolant temperature was $85^{\circ} \mathrm{C}$ ).

On the basis of the coefficient of variation $\mathrm{CoV}$ the variation of engine operation was determined in the form of the following indexes: the maximum combustion pressure $P_{\max }$, the engine speed (SPEED), the mean indicated pressure (IMEP), thermodynamic start of combustion $A I_{05}$ (determined on the basis of a $5 \%$ threshold of heat release) and end of the combustion $A I_{90}$ (defined as the 90 per cent value of the maximum heat release). Subsequently, the parameters specifying the combustion engine operation were determined: the cycles with the most significant dispersion of the maximum pressure values $\left(P_{\text {cyl-min }}, P_{\text {cyl-max }}\right)$ and the cycles with the highest angle values for which the extreme pressure values occurred in the cylinder $\left(A P_{\min }\right.$ and $\left.A P_{\max }\right)$. In relation to the characteristics of the pressure in the cylinder the rate of pressure rise after ignition $\left(R_{\max }\right)$ and its occurrence angle $\left(A R_{\max }\right)$ were additionally determined. The parameters describing the heat release process were: the maximum rate of heat release $\left(d Q_{\max }\right)$ and its occurrence angle $\left(A d Q_{\max }\right)$. After completion of the integration, the maximum value of heat release $\left(I_{\max }\right)$ and the angle at which it occurs $\left(A I_{\max }\right)$ were determined.

\section{Analysis of the steady-state conditions of engine operation: idle speed}

\section{Estimation of the engine operational indexes}

The analysis of the engine operational indexes was conducted at two engine speeds during idling. At the speed of 
Table 1 Technical specification of the tested engine and vehicle

\begin{tabular}{ll}
\hline Parameter & Value \\
\hline Model engine & Spark ignited, gasoline direct injection (air-guided system) \\
Engine type & 4-Cylinder, in-line, turbocharged \\
Timing belt drive & Two shafts in the head \\
Length $\times$ width & $82 \times 85 \mathrm{~mm}$ \\
Engine displacement & $1796 \mathrm{~cm}^{3}$ \\
Compression ratio & 9.3 \\
Average effective pressure & $1.8892 \mathrm{MPa}$ \\
Maximum torque at engine speed & $270 \mathrm{~N} \mathrm{~m}$ at $1800-4600 \mathrm{rpm}$ \\
Maximum power at engine speed & $135 \mathrm{~kW}$ at $5250 \mathrm{rpm}$ \\
Transmission & $7-$ Speed, automatic \\
\hline
\end{tabular}

Fig. 2 The measuring system used for the determination of the variation in SI DI engine operation during idling (figure by authors)

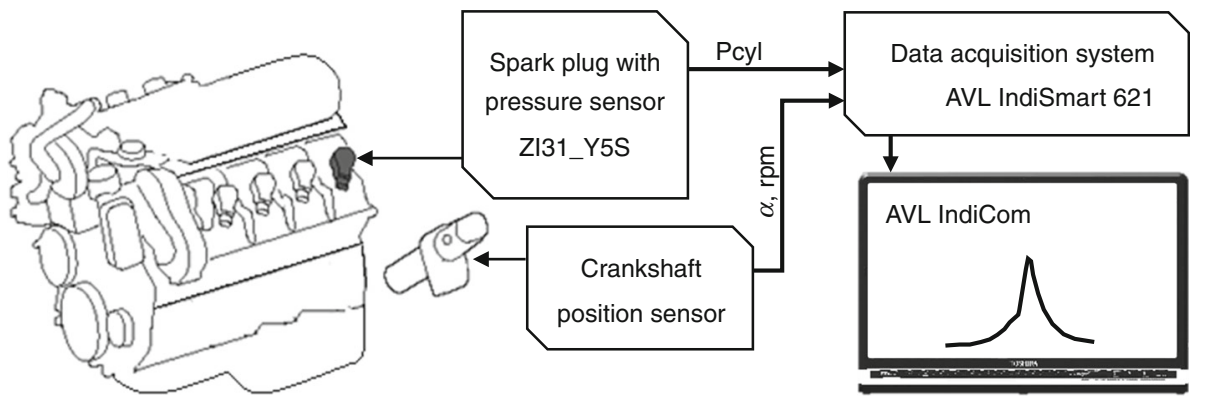

$650 \mathrm{rpm}$ was observed greater repeatability of the engine operation (characterized by the maximum combustion pressure) than in case of increased engine speed (Fig. 3). The engine speed changed within $\pm 5 \mathrm{rpm}$ at a lower value of idle speed and within $\pm 10 \mathrm{rpm}$ at a speed of $750 \mathrm{rpm}$. These changes might be associated with a greater engine load at higher speeds, caused by the lack of drive disconnection.

Analysis of the engine speed intervals, carried out on the basis of Fig. 3, indicates that distributions are close to the normal distribution, and in both variants of the idle speed the distributions are shifted to the left [negative coefficients of skewness-based on Eq. (2)]. The average values almost overlap with the range of values most commonly observed.

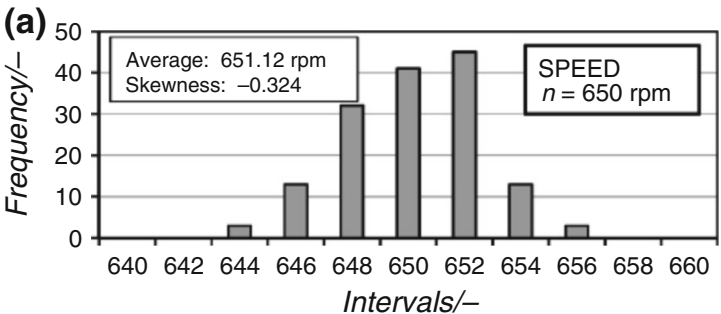

Greater dispersion of the speed $n=750 \mathrm{rpm}$ is caused by the attached gear and running the HOLD function. A lower idle speed $(650 \mathrm{rpm})$ is due to the position $\mathrm{P}$ or disconnecting the drive. It becomes a smaller dispersion of speed (less resistance to mechanical and hydraulic system).

The cumulative analysis of the engine operation cycles was supported by quantitative assessments presented further in the article. They relate to particular cycles of engine operation in idle conditions. The presented analysis is insufficient to assess the variations of engine operation. For this reason additional thermodynamic indexes of engine operation at idling speed were taken into consideration.

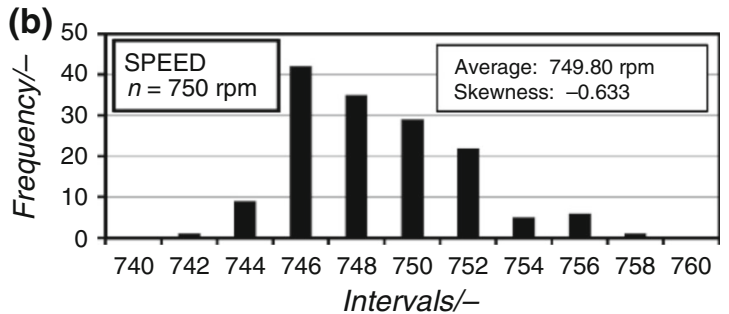

Fig. 3 Ranges estimation of the characteristic parameters variation of the engine operation at idling speed: $\mathbf{a}$ at a speed of $n=650 \mathrm{rpm}, \mathbf{b}$ at $n=750 \mathrm{rpm}$ 


\section{Estimation of variations of engine operation}

The variation of combustion engine operation can be characterized by several parameters, including the value of the maximum combustion pressure (Fig. 4). For the increased engine speed were obtained a little lower values of $P_{\max }$ in the cylinder which indicates that the coefficient of variation $\left[\mathrm{CoV}\left(P_{\max }\right)\right]$ obtains higher values.

The maximum values dispersion of the cylinder pressure also results in different values of the crankshaft crank angle at which the maximum pressure value occurs. As shown in Fig. $4 \mathrm{a}$, the increase of the pressure value in the cylinder results in the shift of the occurrence angle towards the top dead centre. It should be noted that the maximum difference of angles $P_{\text {cyl-max }}$ is more than $10^{\circ}$. At the same time the maximum change of the cylinder pressure amounts to $0.465 \mathrm{MPa}$. The dispersions determined by $\operatorname{CoV}\left(P_{\max }\right)$ and $\operatorname{CoV}\left(A P_{\max }\right)$ amount, respectively, to 6.92 and $7.81 \%$ at the engine speed of $650 \mathrm{rpm}$. An increased idle speed (750 rpm) causes an increase in the $\mathrm{CoV}$ to the value of $9.21 \%$. Also the range of changes of the maximum combustion pressure occurrence angle is greater, resulting in an increase of $\operatorname{CoV}\left(A P_{\max }\right)$ to $12.3 \%$. Considering the literature data referred to, these are acceptable values of those parameters. As it ensues from the individual engine operation cycles analysis, the maximum and minimum values do not appear in the subsequent cycles.

In relation to the heat release rate (Fig. 5a) were obtained dispersions of $\mathrm{CoV}$ parameter amounting to $8.55 \%$. These values are also acceptable. However, here the extreme values of heat release rate do not overlap with the angles of obtaining the maximum rates of the heat release. Despite this, the coefficient of variation amounts to $12.5 \%$ around the mean value.

The dispersion analysis of the centre of combustion $\left(\mathrm{CoC}\right.$ or $\left.A I_{50}\right)$ index indicates existence of a narrow field of its variation at the engine speed of $650 \mathrm{rpm}$ (Fig. 6a).
Despite similar values of heat release at the speed of $n=750 \mathrm{rpm}$ (Fig. 6b), the range of variation of $\mathrm{CoC}$ is higher and ranges from $10^{\circ}$ to $26^{\circ}$. This means higher irregularity and nonrepeatability of the combustion process.

The maximum pressure changes $P_{\max }$ in the cylinder are comparable for both engine speeds and amount to approximately $\pm 0.15 \mathrm{MPa}$ cycle $^{-1}$ (Fig. 7a). The engine speed changes for its lowest values decrease between subsequent cycles and amount to $\pm 3 \mathrm{rpm}_{\text {cycle }}{ }^{-1}$. For the higher engine speed $(n=750 \mathrm{rpm})$ the dynamics is slightly higher and amounts to $\pm 4 \mathrm{rpm} \mathrm{cycle}^{-1}$. This means that the changes observed between the cycles are significantly lower than those presented for the extreme cases in Fig. 4.

The maximum value of the average indicated pressure change at a speed of $650 \mathrm{rpm}$ is much less than at the speed of $n=750 \mathrm{rpm}$ (Fig. 7b). At a lower speed it is \pm 0.1 bar cycle ${ }^{-1}$, and at a higher speed it ranges from 0.6 to -1 bar cycle ${ }^{-1}$. It might be observed that the maximum changes of the mean indicated pressure do not result in the maximum changes of the engine speed.

\section{Comparative analysis of combustion engine operation indexes variation during idling}

Comparative analysis was conducted in relation to two engine speeds. The compilation was made by comparing together the characteristic parameters of the combustion engine operation. The analysis of the maximum pressure in the cylinder (Fig. 8a) indicates dispersion lowers by about $25 \%$ at $650 \mathrm{rpm}\left[\mathrm{CoV}\left(P_{\max }\right)=6.9 \%\right]$ compared to the dispersion at the speed of $750 \mathrm{rpm}\left[\mathrm{CoV}\left(P_{\max }\right)=9.2 \%\right]$. Significantly smaller (up to $36 \%$ ) is also the variation of the occurrence angles of this pressure (they amount, respectively, to 7.8 and $12.3 \%$ ). In relation to the pressure increase rate stability in the cylinder (Fig. 8b) were
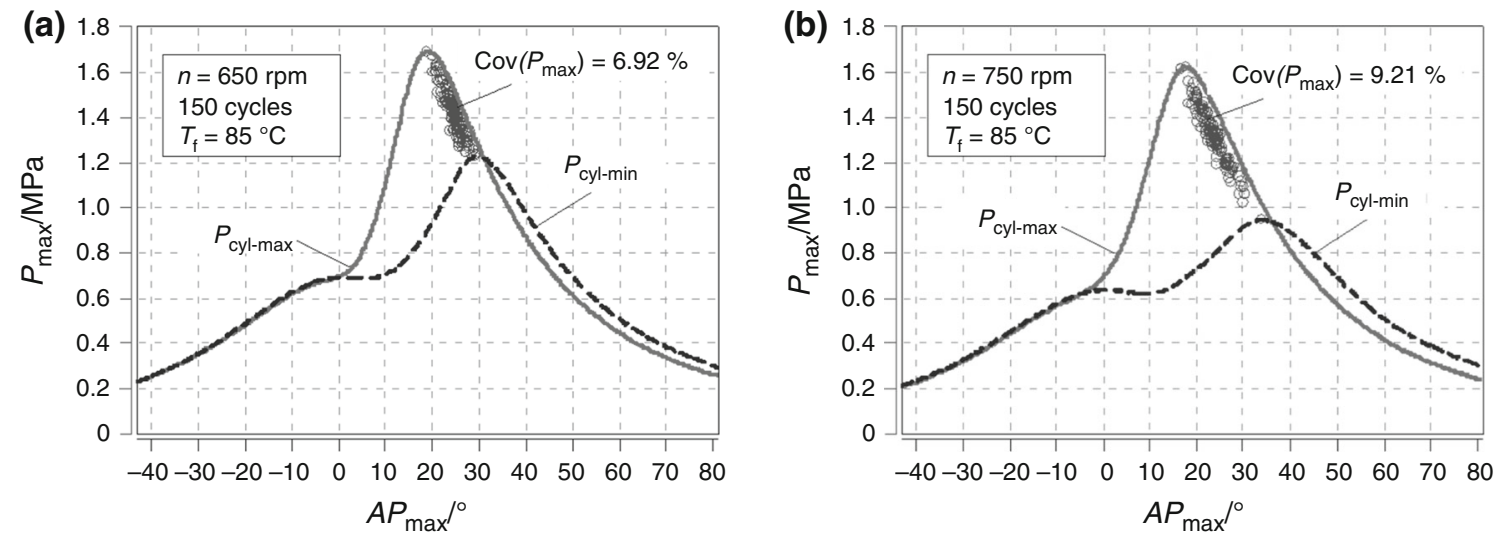

Fig. 4 Analysis of the maximum pressure changes during engine operation at idling for engine speed of: $\mathbf{a} n=650 \mathrm{rpm}, \mathbf{b} n=750 \mathrm{rpm}$ 

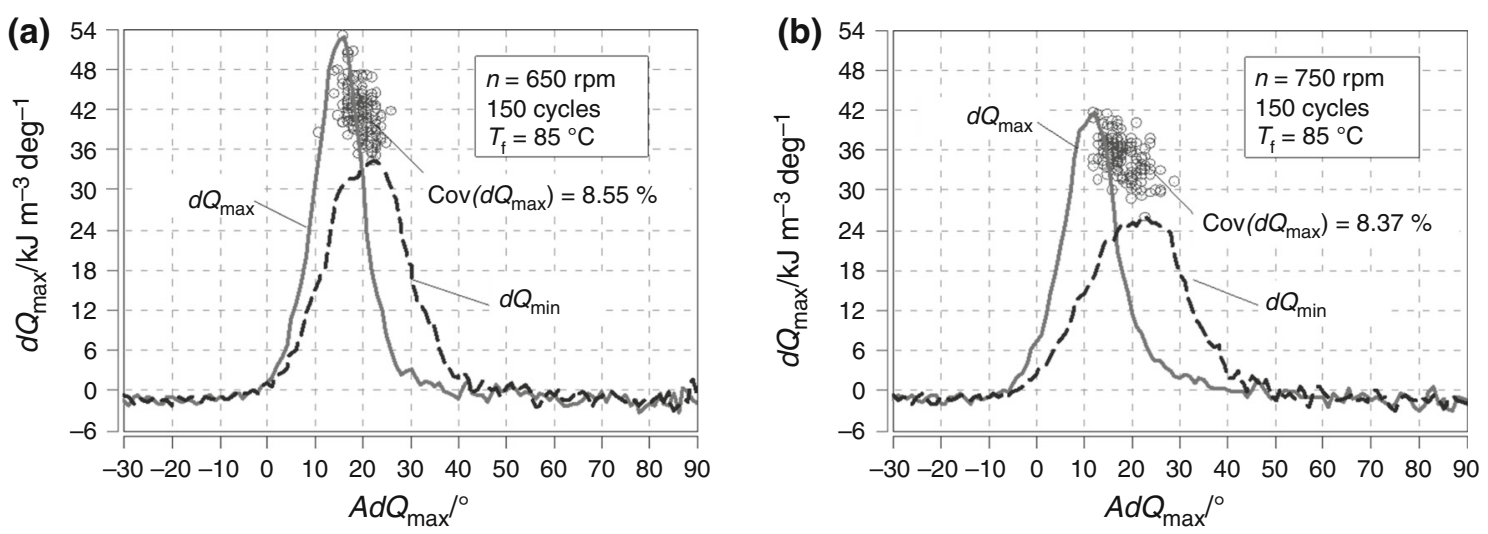

Fig. 5 Analysis of the heat release rate in the idling engine for the speeds of: a $n=650 \mathrm{rpm}, \mathbf{b} n=750 \mathrm{rpm}$
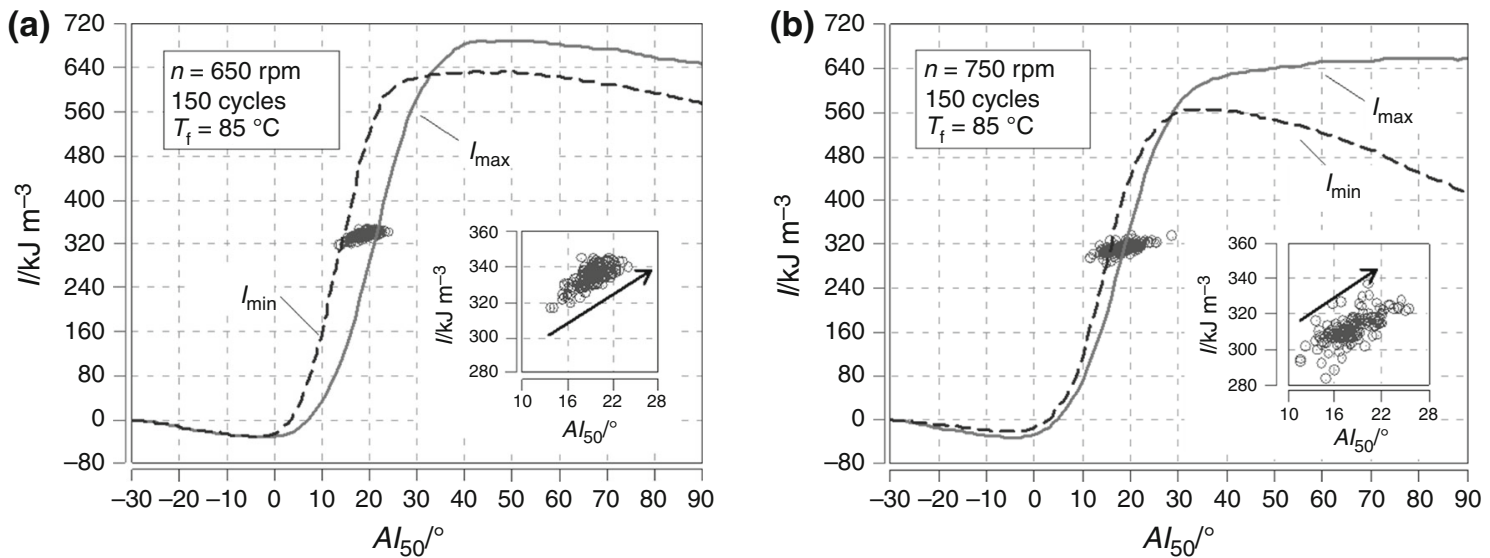

Fig. 6 Analysis of the centre of combustion variation compared to the characteristics of the maximum heat release rate and the angle of its occurrence along with the characteristic data at the engine speeds of a $650 \mathrm{rpm}$, b $750 \mathrm{rpm}$
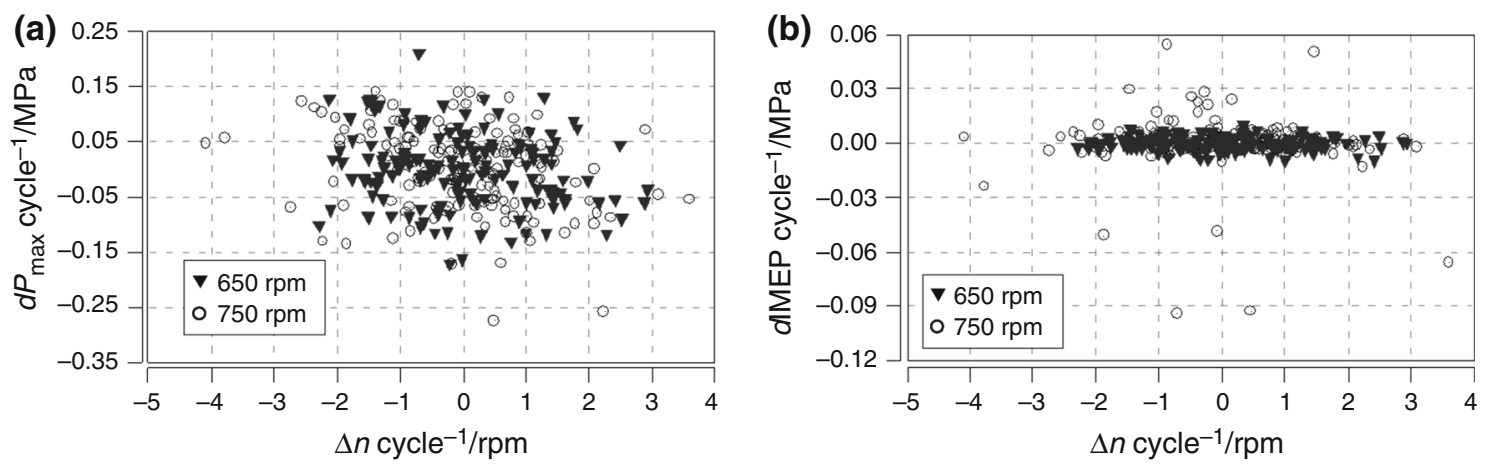

Fig. 7 The changes rate of the parameters analysed during engine operation at idle speed for two speeds: a indicated pressure, $\mathbf{b}$ maximum values of IMEP

obtained significant dispersions at both speeds (over $20 \%$ ). Also the angle of occurrence of this parameter is not constant. Its variation is higher at the speed of $750 \mathrm{rpm}$ $(21.4 \%)$ than at the speed of $n=650 \mathrm{rpm}(13.3 \%)$.

The thermodynamic indexes analysis in the form of heat release rate and its angle (Fig. 9a) indicates values that are acceptable. These are $8.5 \%$ (at $n=650 \mathrm{rpm}$ ) and $8.4 \%$ (at $n=750 \mathrm{rpm}$ ). Slightly larger dispersions refer to the angle at which the maximum heat release rate is obtained (respectively, for the increasing engine speed: $12.5 \%$ and $18.3 \%$ ); however, these values are significantly lower than the angle of the maximum pressure increase rate after the 

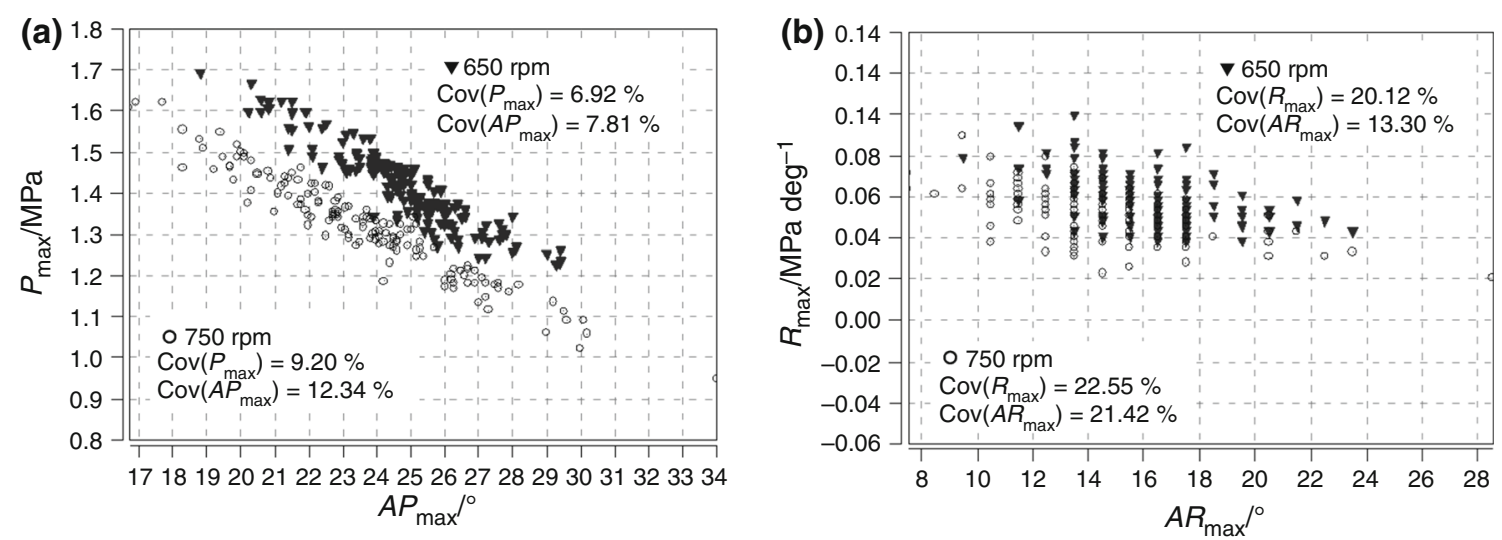

Fig. 8 Analysis of engine operation cycles at two engine speeds: a the maximum pressure and the angle of its occurrence, $\mathbf{b}$ the maximum rate of pressure increase and the angle of its occurrence

ignition. Variation analysis of the heat release maximum values (Fig. 9b) indicates their low values at both engine speeds (at $n=650 \mathrm{rpm}-1.7 \%$, and at $n=750 \mathrm{rpm}-$ $2.7 \%$ ). This suggests a very repetitive combustion process, despite the fact that combustion conditions did not give reasons for such results. Slightly higher values of dispersions take the angle of the heat release maximum values, but these values are lower than $10 \%$ (respectively, 9.6 and $9.8 \%$ ).

Proportionally to the start of combustion process $\left(A I_{05}\right.$ in Fig. 10a) also the end of combustion is delayed. Variation of the values of the process completion only for the lower speed does not exceed $10 \%$. Combustion start variation is significant and amounts, respectively, to 13.6 and $26.4 \%$. A commonly used thermodynamic index for controlling the combustion is the so-called angle of 50 per cent heat release (Fig. 10b). The value of dispersion of this index at lower engine speed amounts to $9.8 \%$ while for higher speed-to $15.5 \%$. This means that the engine with direct gasoline injection requires further research and modification of the combustion control method, as this parameter does not obtain fixed values. Fixed start of combustion (SOC) on the basis of the cylinder pressure characteristics shows greater dispersion ( $n=650 \mathrm{rpm}-42.2 \%$ and for $n=750 \mathrm{rpm}-$ $31.5 \%$ ), which means that this parameter cannot be taken into account during the analysis of the engine operation repeatability.

Although some of the previously presented indexes indicated significant dispersions, the combustion time is characterized by dispersion lower than $10 \%$ (Fig. 11a). The analysis of the change of mean indicated pressure (Fig. 11b) gives the expected results: some of the lowest variations at a speed of $n=650 \mathrm{rpm}$ were obtained, amounting to $2.1 \%$. At a speed of $750 \mathrm{rpm}$, due to the higher dispersions of engine speed, the value of the $\mathrm{CoV}(\mathrm{IMEP})$ is $12.8 \%$. Such significant dispersions of the mean indicated pressure at a speed of $n=750 \mathrm{rpm}$ occur at the fixed thermal engine condition. It should be expected that at a lower temperature of the coolant and engine startup the variation values might be larger at both engine speeds.
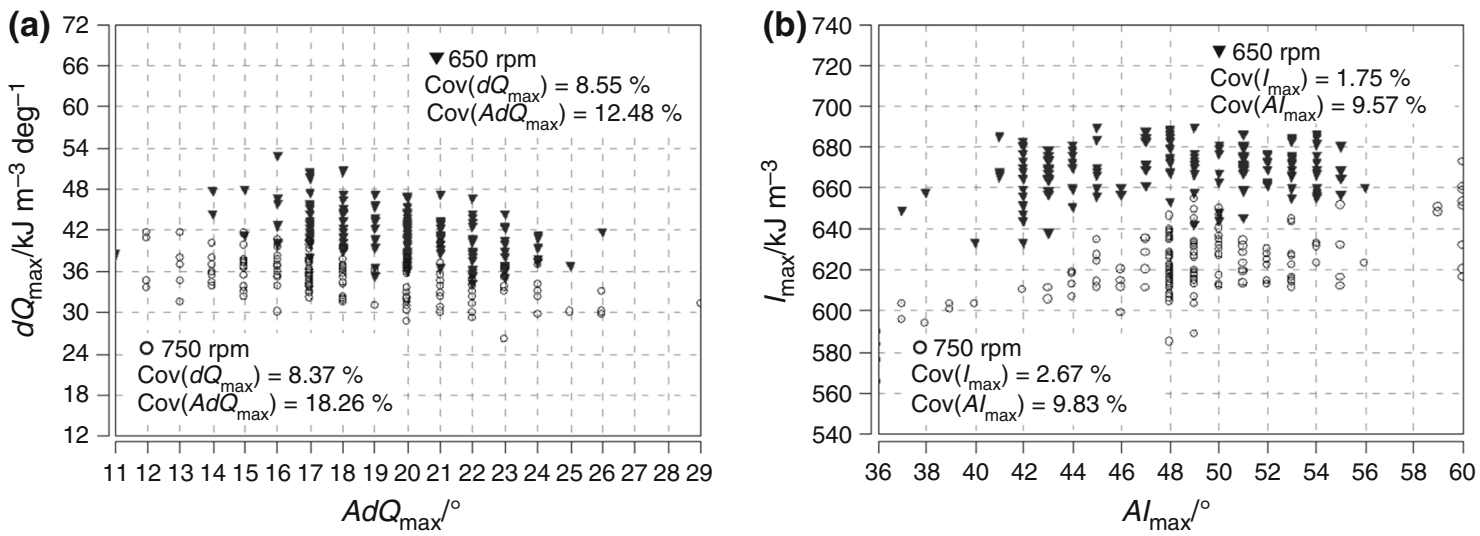

Fig. 9 The thermodynamic analysis of engine operation at two engine speeds: a the maximum heat release rate and the angle of its occurrence, b the maximum heat release and the angle of its occurrence 

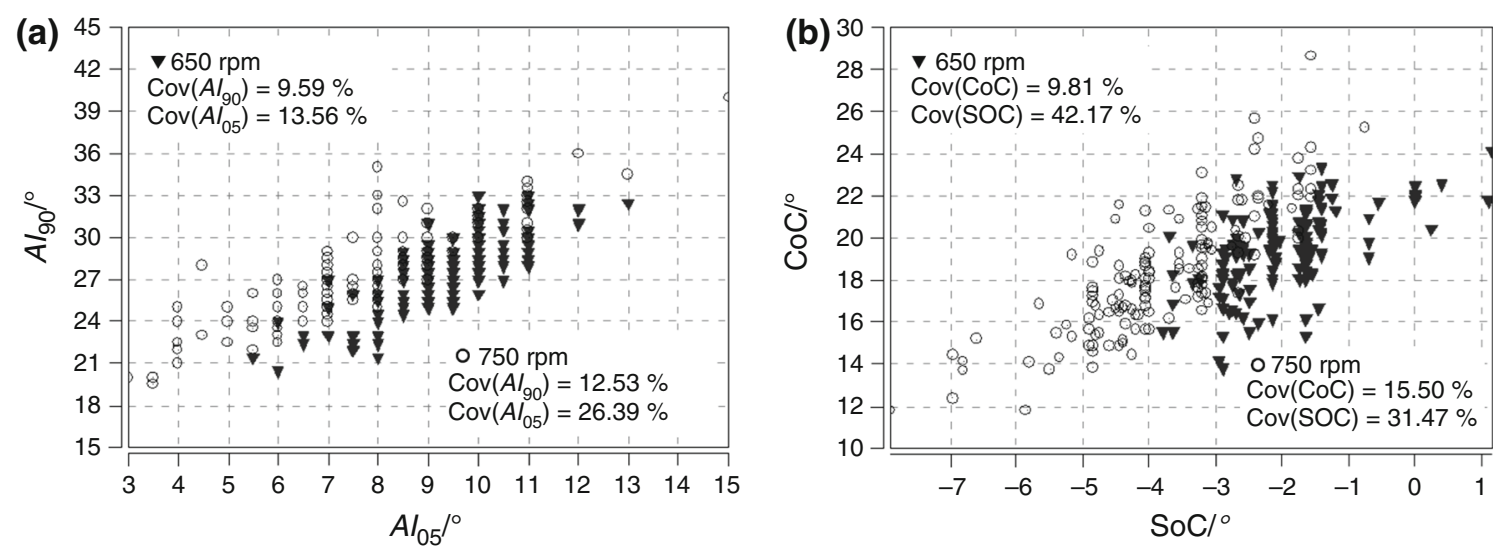

Fig. 10 Thermodynamic analysis of the combustion process at two engine speeds: a at the start and end of combustion, b at the start of combustion and determination of the $50 \%$ heat release
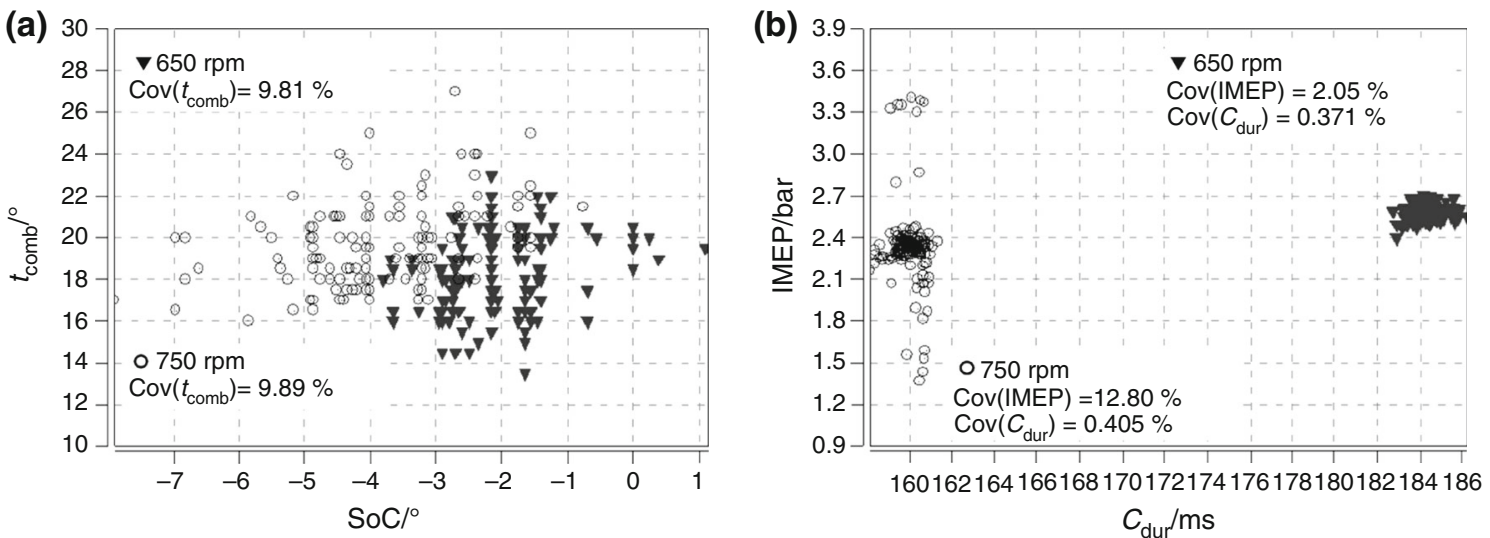

Fig. 11 Thermodynamic indexes of engine operation at two engine speeds: $\mathbf{a}$ at the start of combustion and during combustion, $\mathbf{b}$ time of the cycles duration and mean indicated pressure

\section{Research of the fast-varying processes during acceleration}

\section{The tests of engine operation indexes during free acceleration}

The tests of the engine transient states were carried out in free engine acceleration conditions from the idling to maximum achievable engine speed. In the conditions of the vehicle standstill it is limited to $5500 \mathrm{rpm}$. On the basis of such tests were determined the basic engine operation parameters, including mean indicated pressure designated as IMEP (indicating mean effective pressure). As a part of the research works were also determined the derivatives of these parameters-Fig. 12.

Due to the rapid acceleration the engine obtains the speed close to the maximum permissible limit (the engine controller starts limiting the speed after about 25 operational cycles, which is evidenced by the small increment of
speed-Fig. 12b). For a mild engine acceleration, the maximum engine speed is obtained after about 50 cycles of operation. The rapid acceleration during the tests is characterized by achieving the maximum speed twice as fast compared to the mild acceleration. The mean value of the change in engine speed is approximately $170 \mathrm{rpm}$ during rapid acceleration and $100 \mathrm{rpm}$ during mild acceleration. In the second method of achieving the maximum speed no dose reduction was observed.

Because of the above-presented dependence, for further analysis of the engine operation indexes were utilized the first 25 cycles during rapid engine acceleration and 50 cycles of the engine operation when accelerating in a mild way. Figure 13 illustrates the characteristics of pressure in the cylinder and heat release rate for these two ways of free acceleration.

Rapid acceleration causes more than twofold increase of the pressure in the cylinder (Fig. 13a) and at the same time approximately twofold increase in the rate of heat release. 

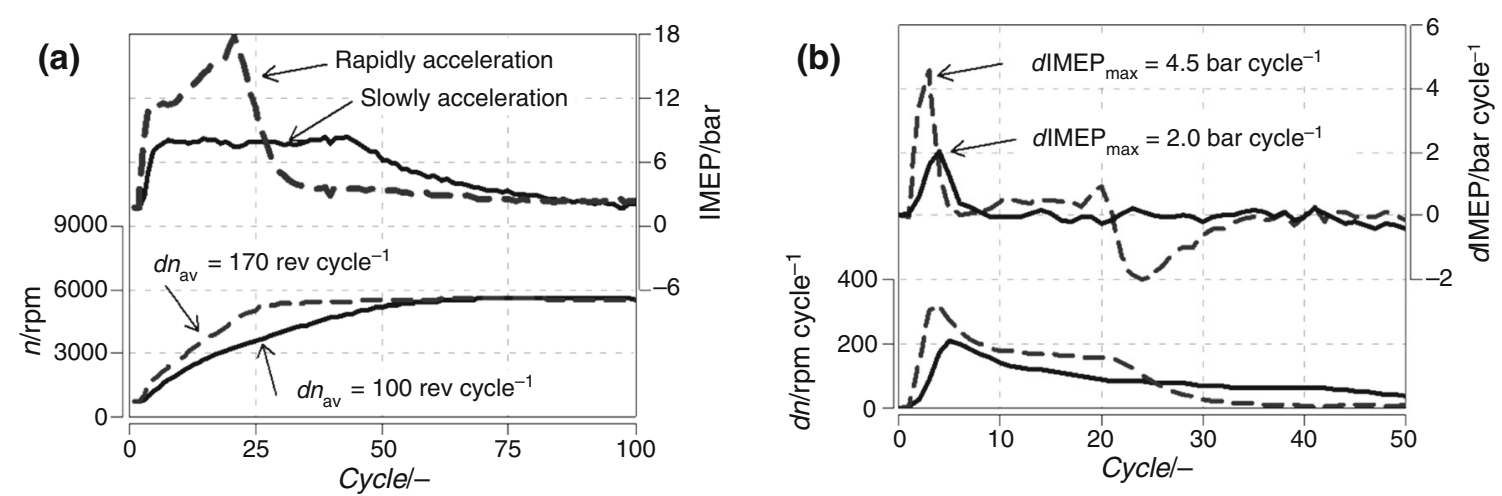

Fig. 12 Analysis of the engine operation indexes during free acceleration: a the engine speed and mean indicated pressure, $\mathbf{b}$ derivatives of these indexes

(a)
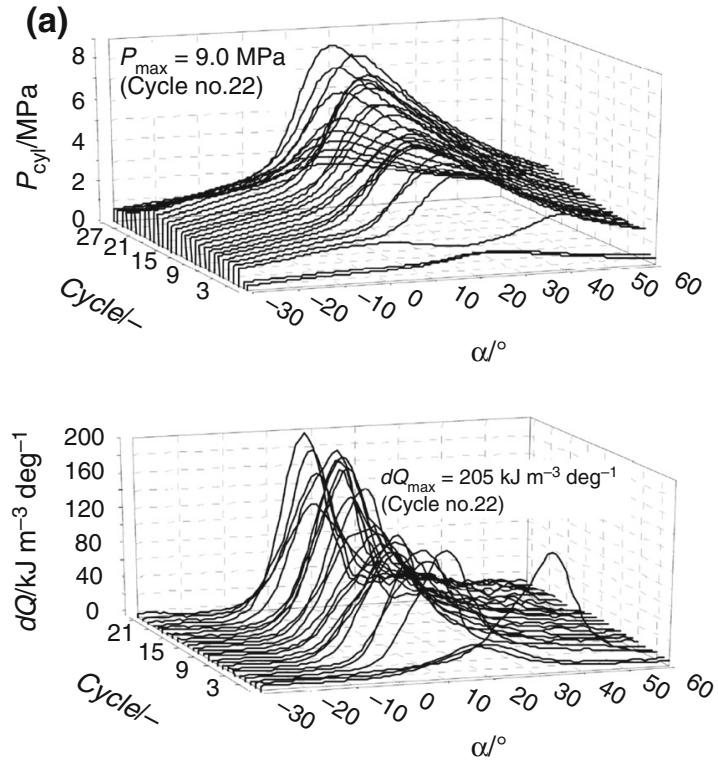

(b)
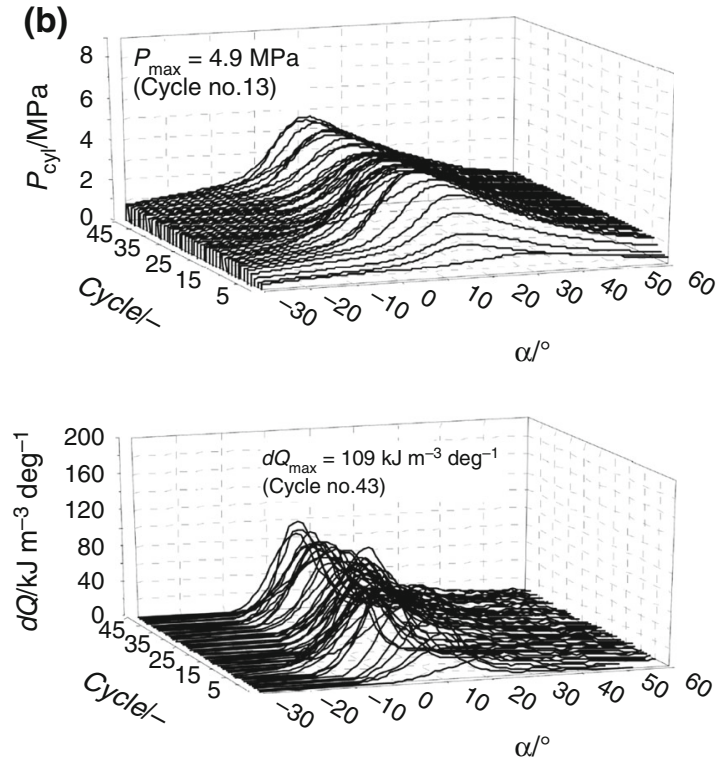

Fig. 13 Subsequent cycles of engine operation during free acceleration: $\mathbf{a}$ at rapid acceleration, $\mathbf{b}$ during mild engine acceleration

Despite the fact that the maximum value of the mean indicated pressure falls within 21 st cycle of engine operation, the maximum value of the pressure in the cylinder $P_{\max }$ occurs for the 22 nd cycle.

\section{The tests of engine operation conditions during vehicle acceleration}

Operation of the engine when accelerating under load was conducted for two operating modes: S mode (Sport) and C mode (Comfort). The tests involved the maximum acceleration of the vehicle to a speed of $100 \mathrm{kph}$. The results of these tests concerning the engine speed and mean indicated pressure changes are shown in Fig. 14. To obtain a vehicle speed of $100 \mathrm{kph}$, the combustion engine carried out 357 cycles of operation of the fourth cylinder. In the figure might be observed a characteristic engine braking for the range from 450 to 550 cycle of operation in S mode and two changes of the gear ratio during acceleration.

The engine operation conditions during vehicle acceleration are compared in Fig. 15. The analysis of these data shows that for the maximum set point of the accelerator pedal, there are no differences in the maximum acceleration conditions of the vehicle in those two modes. Even the change in the engine speed during changing the gear ratios result in equal values of speed and load $(n=4800-5000 \mathrm{rpm})$. The cause of these results is the programming method of the ECU control. The difference between the modes is the faster or slower system response to the request from the driver. This, however, takes place in partial load conditions. In a situation of the maximum vehicle acceleration request from the driver, the controller 
Fig. 14 Engine acceleration conditions for the maximum set point of the accelerator pedal for the two driving modes

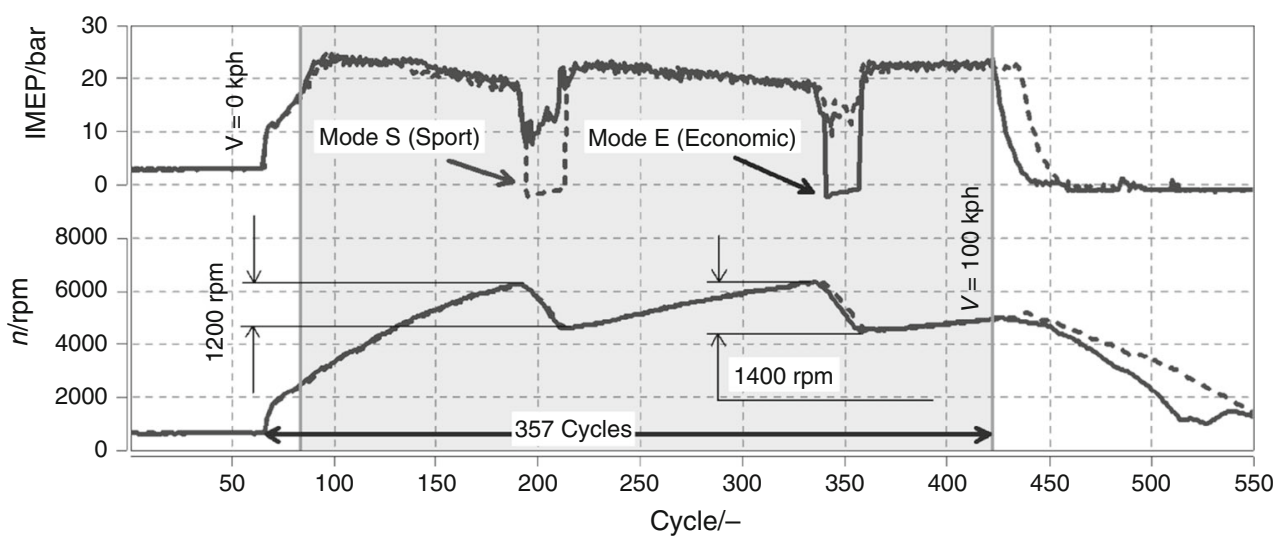

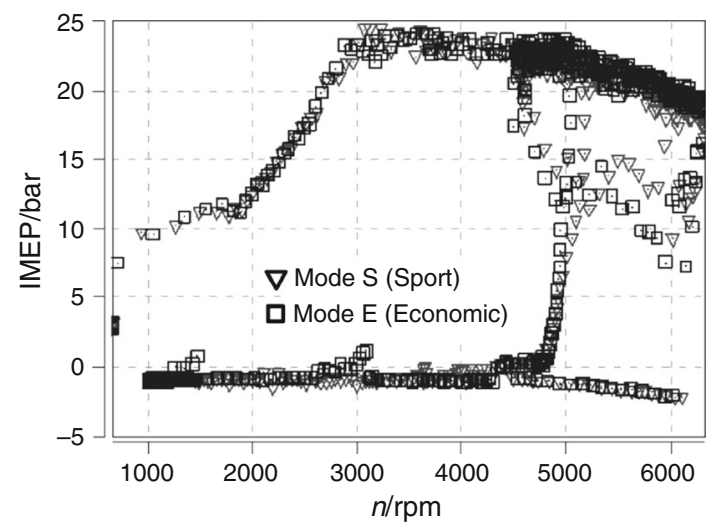

Fig. 15 The engine operation characteristics in coordinates: mean indicated pressure and average engine speed for two driving modes

enforces the same, as quick as possible, acceleration, regardless of $\mathrm{E}$ or $\mathrm{S}$ mode activated.

Due to the same engine speed and mean indicated pressure changes (Figs. 14, 15) for further analysis were selected the vehicle acceleration conditions realized in $\mathrm{S}$ mode (Sport). The acceleration cycles up to achieving the maximum engine speed of about $6260 \mathrm{rpm}$ were taken into account. For so selected part of the engine operation, the operational indexes analysis was conducted with the use of 126 cycles of crankshaft rotations, marked with pictograms in the form of black wheels-Fig. 16.

\section{Analysis of the engine operation indexes changes during acceleration}

The comparative analysis of the engine operation indexes was conducted by determining the values of the following parameters of engine operation: IMEP, $P_{\max }$ and $I_{\max }$. Figure 17 shows the result of these tests, where the range of the vehicle acceleration up to a speed of $100 \mathrm{kph}$ ( $\square-$ 357 cycles) was presented along with the vehicle acceleration range up to obtaining the maximum engine speed

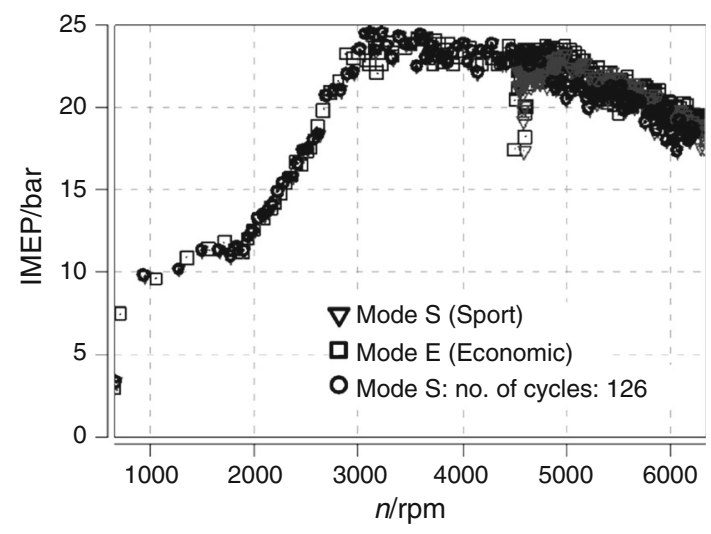

Fig. 16 The subsequent cycles of the engine operation during vehicle acceleration (limited to the conditions of the vehicle acceleration of increasing the engine speed, without conditions at switching the gears)

$(\nabla-126$ cycles) and the conditions of accelerating the idling engine $(\bigcirc-25$ cycles).

During free engine acceleration to the value of $n=2000 \mathrm{rpm}$, the mean indicated pressure range is limited to 12 bar and overlaps with the vehicle acceleration conditions. During increasing the engine speed only partial load is achieved with a limited engine speeds range. The maximum values for the combustion pressure are much smaller than during vehicle acceleration; however, they involve the same range. With the maximum pressure increase in the cylinder increases the angle of its occurrence. The maximum combustion pressure change occurs in the range from 10 to $100 \mathrm{bar}$; however, the angle change is just $6^{\circ}$ of $\mathrm{CA}$ and the relationship takes the linear function form. The heat release rate is also proportional to the maximum value of heat release.

Changes in engine operation indexes between the cycles indicate that during free acceleration are obtained larger engine speed changes (maximum value is $d n=320 \mathrm{rpm} \mathrm{cycle}^{-1}$ ). During applying a load on the engine these values reach approximately $70-80 \mathrm{rpm}$ cy$\mathrm{cle}^{-1}$ (Fig. 18). The rate of the changes of the maximum 

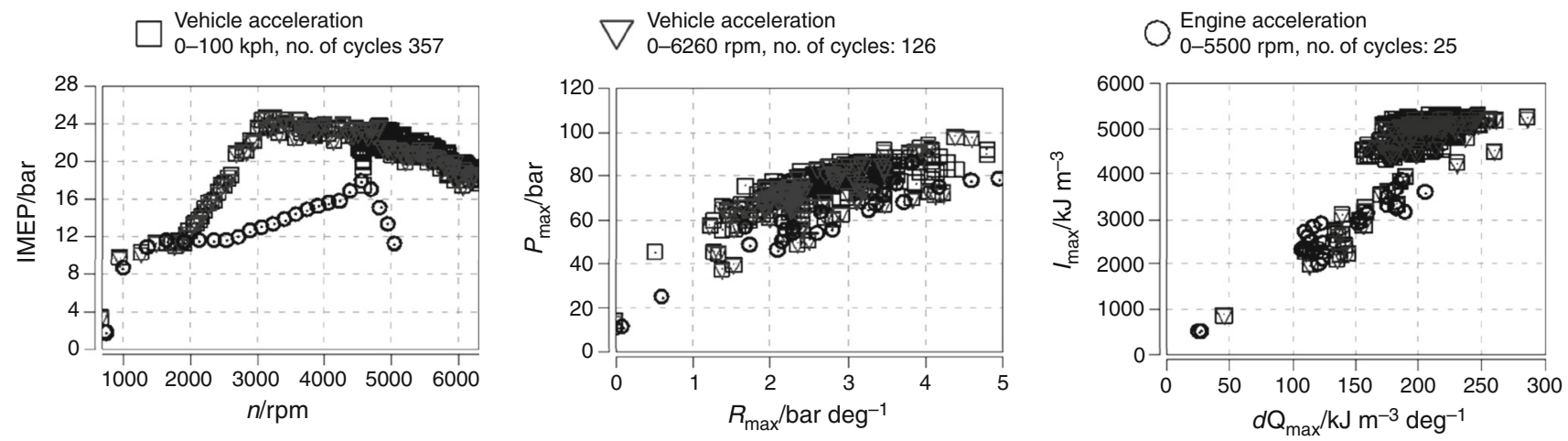

Fig. 17 The assessment of the vehicle accelerating conditions in 25 cycles compared to the full scope of measurement data
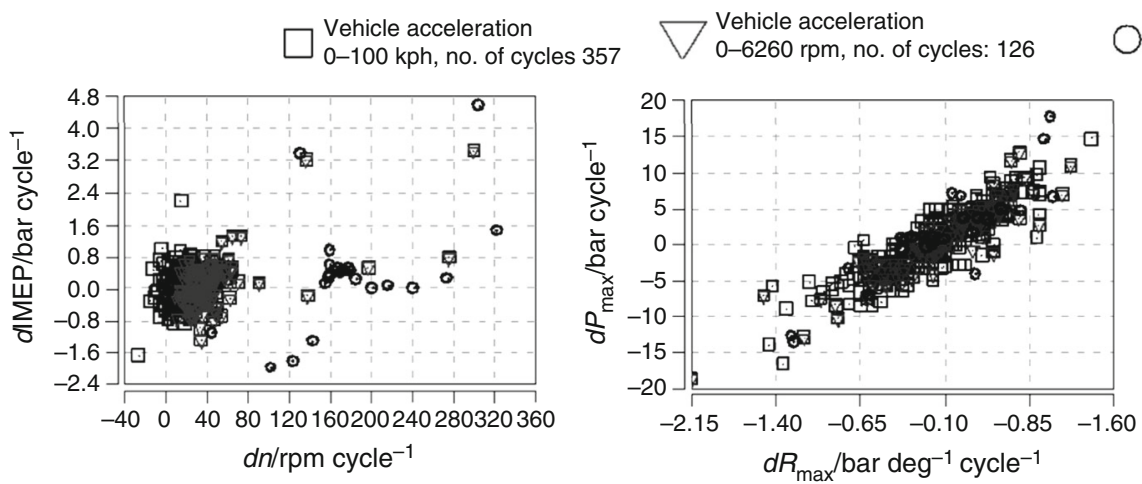

Engine acceleration
$0-5500$ rpm, no. of cycles: 25

Fig. 18 Engine indexes operation variation during its acceleration

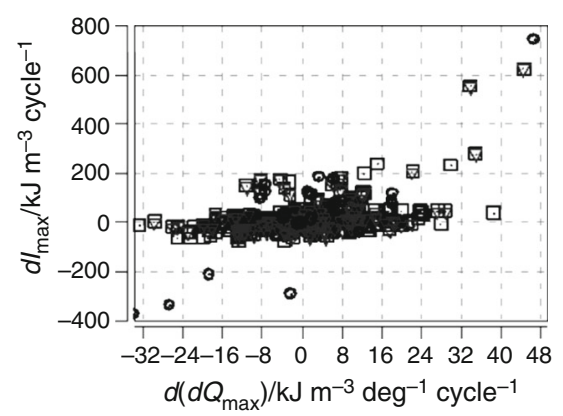

Fig. 19 Variation analysis defined by the $\mathrm{CoV}$ of engine operation indexes

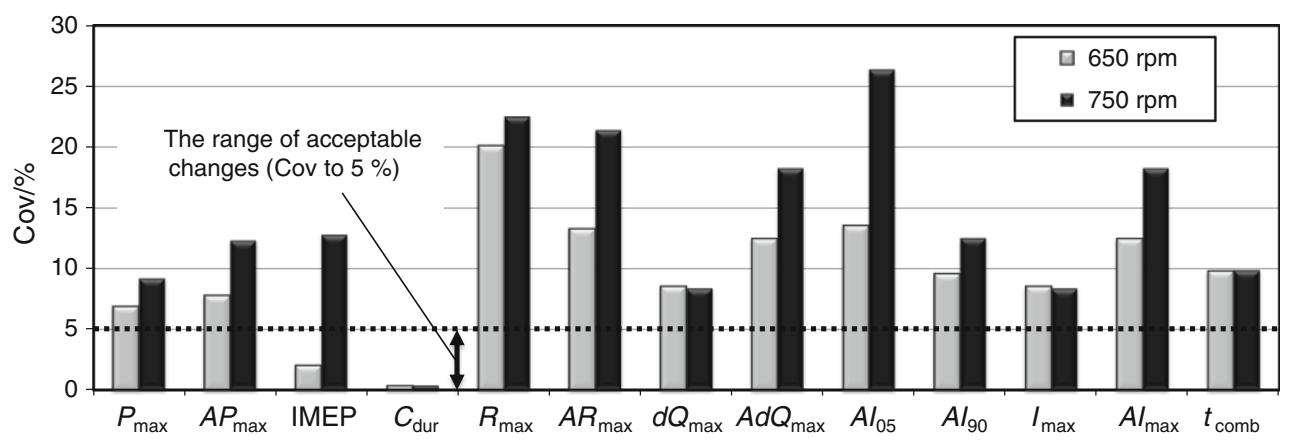

pressure in the cylinder during free acceleration overlaps with the changes range during vehicle acceleration, which indicates the same changes of this index. Also the angle change rate of this pressure overlaps with the changes range during acceleration of a loaded engine. Heat release rate changes compared between the cycles obtain up to about $30 \mathrm{~kJ} \mathrm{~m}^{-3} \mathrm{deg}^{-1}$ cycle $^{-1}$; however, a significant values concentration falls at approximately $0-8 \mathrm{~kJ} \mathrm{~m}^{-3}$ $\mathrm{deg}^{-1}$ cycle $^{-1}$. During free acceleration no significant differences in the obtained values of these indexes were observed.

\section{Conclusions}

The carried out analysis of the coefficients of variation of the engine operation parameters at idle speed indicates the existence of parameters that could, to a significant degree, enable the assessment of the engine operation per cycle. In the tests were used 13 indexes whose variation values are very different. They range from approximately $2 \%$ to over $26 \%$. Despite the fact that the existing limit of $\mathrm{CoV}$ (IMEP) $<10 \%$ is effective for the engine operation variation analysis, the aim is to reduce the dispersions. The 
values below $10 \%$ are met by several engine operation indexes, but not for both engine speeds; this comparison is presented in Fig. 19.

The advanced engine operation control methods, including operation at idle speed, should allow to obtain an acceptable range of $\mathrm{CoV}$ less than $5 \%$. However, such a significant reduction in the engine operation variation value allows selecting only the mean values of indicated pressure and cycle time as the indexes of engine operation repeatability at a speed of $650 \mathrm{rpm}$. For engine speed of $n=750 \mathrm{rpm}$ only the cycle duration time meets the required $\mathrm{CoV}$ below $5 \%$. It is thought that the variation in operation of SI DI engines is so significant that the limit of $5 \%$ will be difficult to meet.

During free acceleration and a loaded engine acceleration are achieved the same engine operation absolute indexes and their changes between the cycles. Different values refer only to the lower obtained mean indicated pressure and higher engine speed changes between the cycles. They result from the absence of loads under these conditions.

The test results confirmed the paper thesis: evaluation of the engine operation variation at idling speed determined only on the basis of the engine speed and mean indicated pressure is unreliable with regard to the thermodynamic indexes of this process. As indicated in Fig. 19 summarizing the test results, only those first two parameters meet the limit of coefficient of variation below $5 \%$. On the other hand, the remaining parameters defining thermodynamic operation of combustion engine indicate greater variation of operation and therefore cannot be used to assess the combustion engine operation stability in the analysed conditions.

The presented in Figs. 17 and 18 comparisons of the engine operation at two tested modes indicate that the thermodynamic indexes of engine operation while accelerating both during standstill and vehicle acceleration are fundamentally different; they arise from different values of the engine load, due to which the possibility of comparing them is limited. Despite this, it is possible to compare the changes of engine operation between cycles, which demonstrates obtaining similar values of the indexes.

Open Access This article is distributed under the terms of the Creative Commons Attribution 4.0 International License (http://creative commons.org/licenses/by/4.0/), which permits unrestricted use, distribution, and reproduction in any medium, provided you give appropriate credit to the original author(s) and the source, provide a link to the Creative Commons license, and indicate if changes were made.

\section{References}

1. Kuhn M. Automotive Powertrain Technologies through 2016 and 2025. In: University of Michigan Transportation Research Institute conference. 2012.
2. He H, Bandivadekar A. Passenger car fuel-efficiency, 2020-2025 Comparing stringency and technology feasibility of the Chinese and US standards. In: International council on clean transportation. 2013.

3. Sing N, Kumar H, Jha MK, Sarma KA. Complete heat balance, performance, and emission evaluation of a CI engine fueled with Mesua ferrea methyl and ethyl ester's blends with petrodiesel. J Therm Anal Calorim. 2015;122:907-16. doi:10.1007/s10973015-4777-8.

4. Pielecha I. Diagnostics of stratified charge combustion under the conditions of multiple gasoline direct injection. J Therm Anal Calorim. 2014;118:217-25. doi:10.1007/s10973-014-3956-3.

5. Chen H, Hung DL, Xu M, Zhong J. A dynamic thresholding technique for extracting the automotive spark-ignition direct-injection pulsing spray characteristics. J Vis. 2014;17:197-209. doi:10.1007/s12650-014-0203-8.

6. Tutunea D. Thermal investigation of biodiesel blends derived from rapeseed oil. J Therm Anal Calorim. 2013;111:869-75. doi:10.1007/s10973-015-4943-z.

7. Zhouxia J, Guoqiang X, Hongwu D, et al. Experimental measurements of thermal conductivity of hydrocarbon fuels by a steady and kinetic method. $\mathbf{J}$ Therm Anal Calorim. 2016;123:891-8. doi:10.1007/s10973-015-4920-6.

8. Valle MLM, Leonardo RS, Dweck J. Comparative study of biodiesel oxidation stability using Rancimat, PetroOXY, and low P-DSC. J Therm Anal Calorim. 2014;116:113-8. doi:10.1007/ s10973-014-3706-6.

9. Wong PK, Tam LM, Li K, et al. Engine idle-speed system modeling and control optimization using artificial intelligence. Proc Inst Mech Eng D J Automob Eng. 2010;224:55-72. doi:10. 1243/09544070JAUTO1196.

10. Shankar KS, Mohanan P. MPFI gasoline engine combustion, performance and emission characteristics with LPG injection. Int J Energy Environ. 2011;2(4):761-70.

11. Heywood JB. Internal combustion engine fundamentals. New York: McGraw Hill Book Company; 1998.

12. Hassaneen A, Varde KS, Bawady AH, et al. A study of the flame development and rapid burn duration in a lean-burn fuel injected natural gas S.I. engine. SAE paper 981384. 1998. doi:10.4271/ 981384.

13. Ozdor N, Dulger M, Sher E. Cyclic variability in spark ignition engines a literature survey. SAE paper 940987. 1994. doi:10. 4271/940987.

14. Pundir B, Zvonow VA, Gupta ACP. Effect of charge non-homogeneity on cycle by cycle variation in combustion in SI engines. SAE paper 810774. 1980. doi:10.4271/810774.

15. Szydlowski H. Theory of measurements. Warsaw: Scientific Publishers PWN; 1981.

16. Tylor JR. Introduction to error measurement analysis. Warsaw: Scientific Publishers PWN; 1995.

17. Saboohi Y, Farzaneh H. Model for developing an eco-driving strategy of a passenger vehicle based on the least fuel consumption. Appl Energy. 2009;86:1925-32. doi:10.1016/j.ape nergy.2008.12.017.

18. Drake MC, Haworth DC. Advanced gasoline engine development using optical diagnostics and numerical modeling. Proc Combust Inst. 2007;31:99-124. doi:10.1016/j.proci.2006.08.120.

19. Franco J, Franchek MA, Grigoriadis K. Real-time brake torque estimation for internal combustion engines. Mech Syst Signal Process. 2008;22:338-61. doi:10.1016/j.ymssp.2007.08.002.

20. Mamala J, Jantos J. Mechanical inertia of power transmission system in acceleration process. Tech Trans Mech. 2008;R105:167-79. 